Disponível em

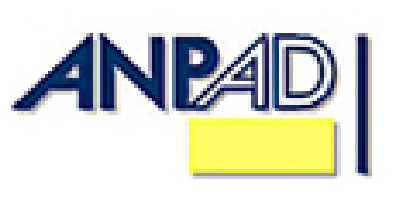

http://www.anpad.org.br/rac

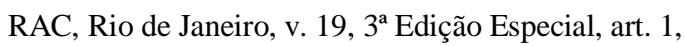
pp. 245-268, Outubro 2015 http://dx.doi.org/10.1590/1982-7849rac20151510

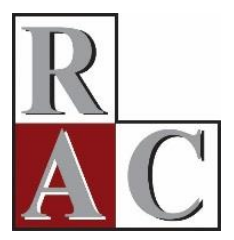

\title{
Com que Cor Eu Vou pro Shopping que Você me Convidou?
}

\section{What Color Should I Go as to the Shopping Mall that You Invited Me to?}

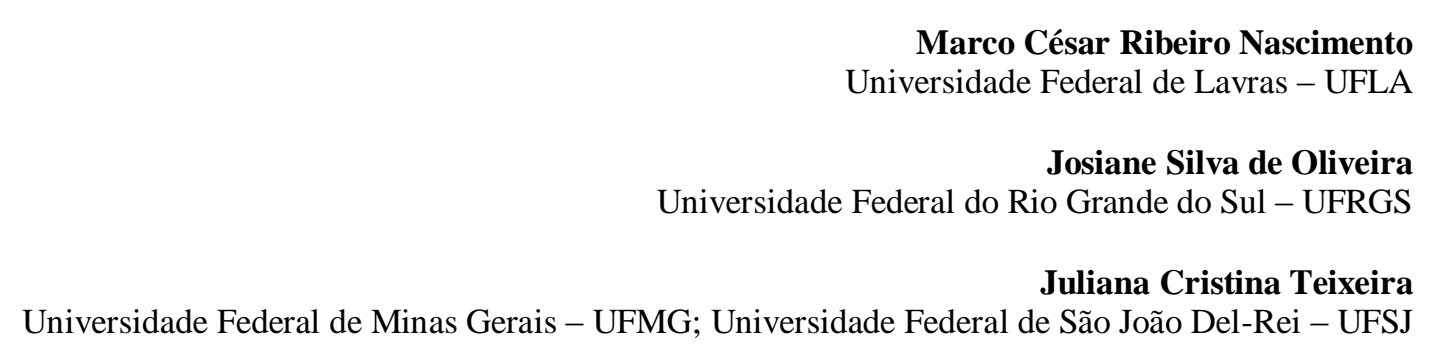

Alexandre de Pádua Carrieri Universidade Federal de Minas Gerais - UFMG

Artigo recebido em 25.06.2013. Última versão recebida em 01.10.2013 Aprovado em 07.10.2013. Publicado online em 26.09.2014. 


\title{
Resumo
}

Neste artigo, analisa-se como os discursos sobre o perfil de usuários dos shoppings centers na cidade de Belo Horizonte evidenciam dois aspectos do contexto sócio-histórico brasileiro: as relações raciais e a segregação socioespacial nos contextos organizacionais. Discutem-se as relações raciais no Brasil considerando a cor como uma construção discursiva e os shoppings centers como organizações que podem se configurar como espaços de segregação socioespacial ao se constituírem como espaços simbolicamente privados de determinados grupos sociais. Utilizou-se a Análise do Discurso da corrente francesa como estratégia metodológica. O corpus de análise constitui-se por discursos presentes na rede social Facebook e se refere a uma imagem que foi veiculada em um portal de notícias sobre a cidade de Belo Horizonte que caracterizava, por meio de seis fotos, o perfil dos frequentadores dos shoppings centers da cidade. Os resultados da pesquisa evidenciam a construção discursiva da cor como dimensão de significação das representações e práticas sociais dos indivíduos que demarcam simbolicamente quem pode e onde deve circular em determinados espaços organizacionais, especialmente nos shoppings centers.

Palavras-chave: cor; raça; shopping center; espaço urbano; segregação socioespacial.

\begin{abstract}
This article analyzes how discourses on user profiles of shopping malls in the city of Belo Horizonte evidence two aspects of Brazilian socio-historical context: race relations and spatial segregation in organizational contexts. We discuss race relations in Brazil considering color as a discursive construction and shopping malls as organizations that can be configured as spaces of spatial segregation that constitute symbolically private spaces for certain social groups. We used French-style discourse analysis as a methodological strategy. The body of analysis was constituted by discourses present in the Facebook social network and refers to an image that was published by a news outlet about the city of Belo Horizonte that profiled the city's shopping mall clientele in a series of six photos. The research results evidence the discursive construction of color as a dimension of meaning of social practices and representations of individuals that symbolically demarcate who can circulate, and where, in determined organizational spaces, especially in shopping malls.
\end{abstract}

Key words: color; race; shopping malls; urban space; spatial segregation. 


\section{Introdução}

Quando os shoppings foram criados, o seu objetivo discursivo era o de alavancar as vendas do comércio varejista (Agostini, 2012). Entretanto, mais do que símbolos de consumo, os shoppings são considerados como espaços carregados de simbolismos também no que se refere à segregação socioespacial nos espaços urbanos.

Com que cor eu vou pro shopping que você me convidou? Essa questão, que parodia uma famosa música de Noel Rosa, é uma resposta utilizada em sentido figurado a uma imagem que foi veiculada em um portal de notícias sobre a cidade de Belo Horizonte (BH) na rede social Facebook ${ }^{(1)}$, resposta essa oriunda da análise do discurso que aqui apresentaremos sobre a imagem e os enunciados a ela vinculados. O título da imagem era Shoppings de BH e a hashtag ${ }^{(2)}$ que acompanhou sua publicação foi \#Humor. O portal de notícias referido está hospedado em uma página do Facebook que pode ser curtida $^{(3)}$ por qualquer usuário da rede social, o que faz com que suas postagens sejam públicas. O portal já foi curtido por 158.013 usuários, o que faz com que esse número de pessoas possa acompanhar diariamente as notícias publicadas.

No dia 23 de janeiro de 2013, a referida imagem foi publicada apresentando seis fotografias que caracterizariam alguns shoppings da cidade de BH: Pátio Savassi, Diamond Mall, Shopping Cidade, Boulevard Shopping, BH Shopping e Minas Shopping. O Pátio Savassi foi vinculado à fotografia da banda Restart, formada por jovens garotos que vestem roupas coloridas. Ao Diamond Mall, é vinculada uma fotografia do casal David Beckham, futebolista inglês, e sua esposa, Vitória Beckham, ambos vestidos sofisticadamente. Para o Shopping Cidade, utilizou-se a fotografia de duas cantoras brasileiras assumidamente homossexuais se abraçando: Ana Carolina e Maria Gadu. O Shopping Boulevard foi caracterizado pela fotografia de um deserto. O BH Shopping, pela imagem de um jovem com uma camisa com o dizer nerd usando óculos de grau. Já o Minas Shopping foi caracterizado pela imagem de um jovem negro (o único negro nas imagens) usando um boné com a aba para trás, brincos nas duas orelhas, piercing no nariz e uma camiseta branca.

Até a data de finalização deste artigo, abril de 2013, a imagem havia sido curtida por 1.064 usuários, compartilhada por 1.926 usuários e recebido 394 comentários, tendo sido elaborada por um dos seguidores do portal. Esses comentários trazem a discussão de Leitão (2005) quando afirma que ocorre nos shoppings centers uma espécie de

seleção 'natural' dos que são convidados a frequentá-los, definida pelo poder aquisitivo de cada um.... Nas cidades maiores, essa distinção é tão nítida que é possível saber de antemão que grupo social se vai encontrar em cada shopping center da cidade (Leitão, 2005, p. 243).

Para utilizar, em sentido figurado, o título Com que cor eu vou pro shopping que você me convidou?, consideramos que as práticas discursivas e sociais envolvidas na composição da referida imagem e também na construção dos referidos comentários, ao estereotiparem os frequentadores de cada shopping center produzem e reproduzem, em termos simbólicos, um convite para que os grupos relacionados às personagens utilizadas se sintam representados, identifiquem-se e curtam as postagens, identificando-as como uma manifestação de humor. Dentre os enunciados postados na rede social como resposta à imagem, a principal menção que se faz nos comentários é ao grupo social que frequenta o Minas Shopping, o qual é caracterizado por um jovem negro com um perfil que socialmente está vinculado à criminalidade e à favela, expressões essas encontradas nos discursos veiculados. Há ainda uma extensão da caracterização desse perfil de frequentador para outros shoppings da cidade: o Shopping Del Rey, o Via Shopping e o Shopping Estação. Por esse motivo, apesar de falarmos em cor em um sentido mais amplo do que estritamente o racial, já que as personagens presentes na imagem refletem vários grupos sociais, veremos que a questão racial será a principal nas discussões.

Após essas considerações iniciais, podemos esclarecer que o objetivo deste artigo é analisar os discursos sobre o perfil de usuários dos shoppings da cidade de $\mathrm{BH}$ que evidenciem dois aspectos presentes em nosso contexto sócio-histórico: (a) as relações raciais no Brasil; e (b) a segregação 
socioespacial nos contextos urbanos. De que maneira a cor, entendida aqui como uma construção social, afeta a permissão simbólica para que determinados usuários frequentem ou não esses espaços organizacionais?

Os shoppings centers são constituídos dentro de uma dinâmica histórica das cidades que foram agregando aos seus centros tradicionais outros centros de consumo, modificando sua dinâmica socioespacial e os usos de seus espaços. Entendemos ainda os espaços e os lugares como sendo socialmente construídos, e não como referenciais geograficamente referidos dentro de uma concepção tradicional da geografia (Daskalaki, Stara, \& Imas, 2008). Consideramos que o espaço urbano representa condição, meio e produto das ações da sociedade ao longo dos tempos (Alves, 2011).

O espaço urbano é influenciado pelas dinâmicas capitalistas e mercadológicas, nas quais espaços específicos para a concretização do consumo devem ser criados (Alves, 2011). No entanto, partimos de uma perspectiva de que o shopping ultrapassa a mera função de atender à dinâmica de reprodução de capital ou de inserir, por exemplo, o consumo como um estilo de vida (o que possui um caráter ideológico). Utilizamos perspectivas críticas a respeito do espaço urbano e de dinâmicas segregatórias nele contidas com base, sobretudo em estudos da geografia urbana que vêm se preocupando com essas temáticas que ainda não são valorizadas no âmbito dos estudos em Administração. Mesmo que alguns estudiosos organizacionais venham se debruçando sobre essas temáticas, ainda é um campo de investigação restrito nesse contexto. Quando se fala em shopping centers, torna-se relevante problematizar dimensões sociais e históricas relacionadas a esses lugares, justamente o intuito deste artigo, ao discutir a segregação sócio-espacial envolvida no espaço do shopping center.

Este estudo traz reflexões relevantes porque, para Leitão (2005), a partir de uma circunstância histórica em que nas cidades a casa disse não à rua, as cidades e os ambientes urbanísticos foram também sendo criados como ambientes de exclusão hostis aos grupos socialmente desprezados. O shopping, nesse contexto, aparece como uma extensão da privatização do espaço, podendo se tornar hostil a determinados grupos sociais.

Ao trazermos essa discussão para o campo dos estudos organizacionais (EOR), estamos trazendo uma visão desnaturalizada do espaço organizacional. Entendemos os espaços organizacionais como sendo construções sócio-históricas que refletem dinâmicas sociais mais amplas e que reproduzem características das dinâmicas socioespaciais dos espaços urbanos. Trazemos também para o contexto das discussões empreendidas nos EOR a dimensão racial para a análise do social e do organizacional, nos inserindo em um debate que, na visão de Rosa (2012), ainda precisa ser feito nesse campo de pesquisas. $\mathrm{O}$ artigo está estruturado da seguinte forma: discutimos as relações raciais no Brasil; a ideia dos shoppings como espaços de segregação social inseridos nos espaços urbanos; apresentamos os caminhos metodológicos; as análises dos discursos e, por fim, as considerações finais e as referências.

\section{Relações Raciais no Brasil}

Os estudos sobre as relações raciais nos espaços organizacionais têm evidenciado que o fator racial é um importante arbitrário para determinar a posição social dos sujeitos na sociedade. Isso porque a raça como categoria de análise discursiva e não biológica tem como efeito a constituição de mecanismos de classificação das representações e práticas dos sujeitos sociais (Rosa, 2012). Neste artigo, assim como Rosa (2012), retomamos as discussões de Hall (1999, p. 63), que considera a raça como uma:

categoria discursiva e não uma categoria biológica. Isto é, ela é uma categoria organizadora daquelas formas de falar, daqueles sistemas de representação e práticas sociais (discursos) que utilizam um conjunto frouxo, frequentemente pouco específico, de diferenças em termos de características físicas e corporais - cor da pele, textura do cabelo, características físicas e corporais, etc. - como marcas simbólicas, a fim de diferenciar socialmente um grupo do outro. 
Nesse sentido, as discussões sobre as relações raciais são deslocadas tão somente de seus aspectos biológicos, ocupando também o campo semântico e de significação de debates sobre os aspectos sociais que sustentam o entendimento do que é ser negro, branco, índio, mestiço, dentre outras formas de classificação humana, em diferentes sociedades pelo mundo. Essas diferenciações de significação evidenciam que as relações raciais não possuem apenas um conteúdo étnico-semântico, mas também político-ideológico de hierarquização (Munanga, 2005/2006). Pois, discutir relações raciais é colocar em discussão as diferentes formas de relações de poder que permeiam a sociedade. O problema fundamental das discussões sobre relações raciais está no processo de hierarquização, desumanização e de justificativa da discriminação existente entre as diversas populações e que, no Brasil, torna-se evidente quando analisamos historicamente a posição que a população negra ocupa no país (Munanga, 2005/2006). Desde o século XX, diversos pesquisadores têm analisado os efeitos das assimetrias das relações raciais sobre a população negra. Da dimensão econômica à ocupação dos espaços sociais, o que se tem observado é um processo de segregação generalizado da população negra (Departamento Intersindical de Estatística e Estudos Socioeconômicos [DIEESE], 2012).

Desde os primeiros debates acerca do racismo científico, que buscava elementos da ciência para justificar a escravidão dos negros, existe um silenciamento das relações de poder que marcam as relações raciais brasileiras. Isso se torna ainda mais evidente quando analisamos o mito da democracia racial (Freyre, 1961). Pautado na ideia de que, no Brasil, negros, brancos e índios teriam estabelecido um processo de miscigenação harmonioso, ao contrário do que se pode observar nos Estados Unidos (Atkinson, Rosati, Berg, Meier, \& White 2013; Raynor, 2009), África do Sul (Ikejiaku, 2009; Worby, 2009) ou Reino Unido (Kenny \& Briner, 2013), por exemplo. O mito da democracia racial sustenta que o Brasil não é um país racista, e que colocar em discussão o conceito de raça e de relações raciais é estimular um conflito não observável na sociedade brasileira. Um dos elementos utilizados para sustentar essa ideia de miscigenação democrática é a figura do mestiço (Sansone, 1996).

Correa (1996) destaca que a figura do mestiço despolariza as questões das relações raciais no Brasil criando um continuum que prioriza a alocação situacional para as classificações sociais. No imaginário social, a mestiçagem corresponde à solução do problema da contradição entre a suposta democracia racial brasileira e a desigualdade social entre brancos e negros no país, pois cria um terceiro elemento de mediação nessa relação (Correa, 1996). A justificativa para o desfavorecimento da população negra se torna uma questão econômica, pois existiria um encontro harmônico das raças no país, e, portanto, o acesso à maior renda pelos negros faria com que esse possível cenário de discriminação cessasse no Brasil. Entretanto, diversos estudos têm evidenciado que, mesmo com maior acesso à renda, o acesso dos negros a alguns espaços sociais, especialmente no mercado de trabalho, ainda é restrito (DIEESE, 2012). E os mecanismos de funcionamento das relações raciais no Brasil se exprimem muito mais via preconceito racial de marca do que preconceito racial de origem, este segundo característico dos EUA (O. Nogueira, 2007).

Preconceito racial, de acordo com O. Nogueira (2007, p. 292), é uma "disposição (ou atitude) desfavorável, culturalmente condicionada, em relação aos membros de uma população, aos quais se têm como estigmatizados, seja devido à aparência, seja devido a toda ou parte da ascendência étnica que se lhes atribui ou reconhece". Caso esse preconceito seja exercido no que se refere à aparência das pessoas, tendo por pretexto os traços físicos do indivíduo, a fisionomia, os gestos, o sotaque, O. Nogueira (2007) considera como sendo preconceito de marca; e se a manifestação do preconceito ocorre pela descendência do grupo étnico do indivíduo, diz-se que é de origem.

No Brasil, o preconceito de marca se torna mais evidente tanto pelo processo de miscigenação quanto pela difusão do mito da igualdade racial. Determinar quem é negro pela sua origem se torna impossível devido ao continuum étnico e racial que prioriza o relacional para as classificações sociais, especialmente pela construção da figura do mestiço (Correa, 1996; Mountian \& Calvo-Gonzalez, 2012; Soares, 2012), porém não destituindo seus efeitos concretos ou subversivos de segregação na sociedade. É um tipo de preconceito que assimila o diferente ao mesmo tempo em que o pretere. Isso é o que possibilita, no Brasil, o preconceito de marca conviver lado a lado com a intimidade das pessoas caracterizando, especialmente, um tipo de preconceito racial de marca associado à posição do sujeito negro na sociedade. É por isso que se torna comum legitimar falas como eu não tenho preconceito. Eu

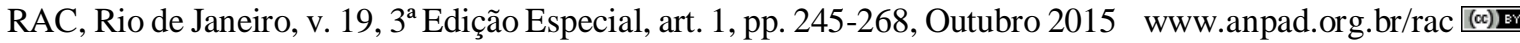


tenho um amigo negro, estabelecendo sempre um lugar fora das relações sociais, mas íntimo no seio da sociedade. Sendo assim, nos diferentes lugares que os sujeitos ocupam na sociedade, primeiramente, observamos a prevalência do preconceito de marca.

O conceito de discriminação se refere à operacionalização prática do preconceito no cotidiano de vida dos indivíduos. Ocorre quando essa disposição desfavorável em relação aos membros de uma população, que denominamos neste artigo de preconceito (O. Nogueira, 2007), limita o acesso dos indivíduos aos bens simbólicos e materiais produzidos pela sociedade, resultando na criação de condições de confirmação dos estigmas que sustentam o preconceito (Coelho, 2011).

É a isso que Sansone (1996) chama atenção quando afirma que as relações raciais no Brasil se constituem em áreas duras, áreas moles e espaços negros. As áreas duras são aquelas onde não há possibilidade de circular no continuum racial. Nesse lugar não existe o moreno, mulato, mestiço. Existe a posição determinada socialmente para o negro que dificilmente consegue transitar além dela. As áreas duras são o mercado de trabalho, o mercado matrimonial e da paquera e os contatos com a polícia dimensão institucional da sociedade. Nesses espaços são evidentes os mecanismos de ação do preconceito de marca, ao estabelecer, por exemplo, os postos de trabalho relacionados aos negros; as relações amorosas e afetivas - as mulheres negras como objeto sexual, pois a mulata é a tal na sociedade brasileira (Correa, 1996); e a questão da imagem do negro associado à criminalidade.

Para Sansone (1996), as áreas moles são os espaços onde os negros não têm dificuldade de circulação, podendo até mesmo ser prestigiados por suas atuações, voltadas ao lazer em geral, a exemplo do esporte ou do carnaval. Sansone (1996) fala ainda dos espaços negros implícitos e dos espaços negros explícitos. Nos primeiros, a exemplo de algumas Congregações Religiosas, ser negro não é um obstáculo, pois falar em termos de cor e racismo não faz parte das relações sociais. Nos espaços negros explícitos, os elementos culturais dos negros são valorizados, como nos blocos afros, terreiros de candomblé ou rodas de capoeira.

A ocupação pelos negros dos espaços considerados como áreas duras possibilitaria a constituição de um processo de ressignificação político-ideológica dos lugares estabelecidos para a população negra na sociedade. Rosa (2012) e Conceição (2009) destacam, por exemplo, o próprio espaço de debates em estudos organizacionais como sendo possivelmente parte dessas áreas duras por ser um espaço silenciado de debates sobre as relações raciais no Brasil. Nosso foco neste artigo é justamente analisar como se configuram os discursos sobre as relações raciais no país a partir de um espaço organizacional (e, portanto, social) que pode ser considerado uma área dura específica de trabalho e de consumo: os shoppings centers.

\section{Os Shoppings como Espaços de Segregação Social no Contexto Urbano}

O primeiro shopping center brasileiro foi o Shopping Iguatemi, construído em 1966, em São Paulo. Foi na década de 1980 que ocorreu um boom de construções de shoppings centers no país, concentrados principalmente na região sudeste (Alves, 2011). A cidade de Belo Horizonte foi marcada, no século XX, por um modernismo que trouxe alterações em termos de historicidade da cultura urbana. Objetivou-se a construção de um homem moderno por meio de interferências (políticas, das artes e da arquitetura) em sua produção cultural e, o que é especificamente importante para este artigo, em sua espacialização econômica. Esse processo gerou uma progressiva segregação social (Bahia, 2005). Até abril de 2013, o Brasil tinha 460 shoppings, com previsão de inauguração de outros 43 neste ano. Desse total de shoppings, 257 estão localizados na região Sudeste (55,9\%). Minas Gerais é o terceiro estado com o maior número de shoppings (39), sendo superado por São Paulo (154) e Rio de Janeiro (58). A cidade de BH tem atualmente 21 shoppings, sendo a terceira capital com o maior número de shoppings (Associação Brasileira de Shopping Centers [ABRASCE], n.d.). 
Para Leitão (2005), a configuração atual das cidades demonstra a continuidade de uma segregação socioespacial que já era característica em nossa sociedade desde o período colonial. Para a autora, há demarcações simbólicas que nos remetem às separações entre a casa-grande e a senzala, discutidas por Freyre (1961), e que podemos relacionar às delimitações que compõem, em termos raciais, as formas de segregação que Sansone (1996) denominou de áreas duras, áreas moles e espaços negros. Segregação é um processo de "localização de grupos sociais semelhantes em um mesmo espaço" (L. T. Andrade, 2002, p. 4). Essa noção de semelhança pode dizer respeito a diversos fatores, como classe social, renda, gostos, interesses pessoais ou fatores raciais, como já discutido neste artigo, especialmente no que se refere ao preconceito de marca. A materialidade do preconceito de marca, expresso no corpo, nos gestos e na inscrição dos indivíduos no espaço social, relacionada à construção da figura do mestiço no Brasil, possibilita priorizar a dimensão relacional das classificações sociais, evidenciando a participação ativa dos indivíduos na delimitação da localização de diversos grupos sociais em diferentes espaços na sociedade. É essa delimitação realizada pelos indivíduos de quem pode e onde dever circular em diversos espaços sociais que possibilita o entendimento de que o conceito de segregação envolve também a noção de discriminação (L. T. Andrade, 2002), pois implica em práticas que também são construídas pelos indivíduos para hierarquização de grupos sociais.

Leitão (2005) considera os shoppings centers como lugares que simbolizam esse processo de segregação (L. T. Andrade, 2002), podendo se constituir como áreas duras, nos conceitos discutidos por Sansone (1996), pois, no Brasil, não desempenham simplesmente a função de centros de compra e de serviços. Os shoppings centers são, no nosso país, um espaço de acolhimento dos iguais, "rejeitando claramente aqueles que não pertencem ao mesmo grupo social -, à semelhança do que fazia a casa patriarcal" (Leitão, 2005, p. 243), caracterizando também um espaço de discriminação. Bittencourt (2012, p. 92) destaca a existência de uma ideologia excludente na própria configuração espacial do shopping, que se "configura na sociedade contemporânea como um fenômeno de assepsia social para que a classe abastada possa melhor se dedicar ao ato de consumo". Para o autor, há um sistema panóptico na topologia do Shopping Center que se refere a uma dinâmica de favorecimento ao controle, na medida em que todos podem ser vistos de vários ângulos, contribuindo para uma dinâmica de controle de comportamentos.

Nosso objetivo é discutir os mecanismos que podem constituir os shoppings como áreas duras, na abordagem de Sansone (1996). L. M. Andrade (2012), ao discutir o shopping center no contexto da América Latina, considera o mesmo como uma figura paradigmática do discurso colonial, envolvendo relações de poder e racismo. Para o autor, o shopping center é mais do que um centro comercial que se tornou uma catedral da marca ou a Meca da mercadoria, é um lugar no qual várias contradições do capitalismo tardio se fazem presentes. Na visão de L. M. Andrade (2012, p. 218), em contextos latinoamericanos marcados historicamente pelo colonialismo, os shoppings se tornaram "um dos objetos discursivos mais representativos da narrativa neocolonial". Ele traz a reconstrução de discursos que estavam presentes no imaginário social desde o século XVI, como a divisões de classe.

Assim como emergem os discursos que sustentam o consumo como uma expressão da posição social que se ocupa ainda hoje no contexto latino-americano, há uma grande influência e tipificação do padrão de comportamento das metrópoles coloniais e também dos EUA. Copiando os modelos de consumo de países mais desenvolvidos, a população desses países vê nos shoppings uma possibilidade de se adequar aos padrões de consumo e lazer hegemônicos (L. M. Andrade, 2012). Os shoppings centers brasileiros reproduzem certa sacralização de grandes marcas e, principalmente, de grandes marcas internacionais que estabelecem um padrão de consumo hegemônico, o que aumenta de significância na medida em que se aumenta o poder aquisitivo da população-alvo desses shoppings. Assim, embora de uso coletivo, tornam-se espaços simbolicamente privados (Herzog, 2013; Leitão, 2005). O shopping center e seu público alvo desejado, bem como sua localização, delimitam inclusive o tipo de loja que ele vai ter. Embora haja lojas que se espalham pelas diversas segmentações de shoppings, há direcionamentos específicos que determinam a presença ou não de determinado tipo de loja ou até de marca de roupas nos variados shoppings, segregando espacialmente as pessoas que o frequentam o que, com efeito, possibilita constituí-los como áreas duras para aos negros. 
O shopping center também representa para Alves (2011) a criação de novas centralidades urbanas. Para a autora, as cidades passaram por uma transformação histórica em que deixaram de ter apenas um centro urbano tradicional, sendo inicialmente monocêntricas, para atualmente contar com uma diversidade de centros em virtude da intensificação do processo de urbanização. Trata-se de um processo de descentralização no que se refere especificamente à ideia de um único centro urbano tradicional, para a ideia da existência de vários centros, ou seja, para a ideia de uma cidade multi(poli)cêntrica. É importante ressaltar, no entanto, que a existência desses outros centros não implica que o antigo centro tradicional não deixe de ser importante.

Centralidade é uma noção que envolve o processo de se amontoar algo, o que é uma ação tipicamente social e que vem então sofrendo alterações ao longo do tempo (Alves, 2011). Além de um centro urbano tradicional em que se concentram atividades de comércio, de serviços, de gestão pública e privada (Alves, 2011), o shopping center representa outra forma de centralidade que inclusive contribui para uma dinâmica de segregação social. Para Alves (2011), o surgimento das diferentes centralidades ocorre, entre outros aspectos, com base nas diferentes condições socioeconômicas associadas aos diferentes lugares, o que faz com que a centralidade assuma um caráter seletivo.

Com mais opções de centralidade sendo construídas, influencia-se positivamente na manutenção da convivência dos iguais, ou seja, esse processo favorece que grupos homogêneos possam frequentar os mesmos lugares (Alves, 2011) ao invés de terem que conviver com diferentes grupos em um único centro urbano, já que essa ideia de centro urbano remete a oferta e bens e serviços essenciais. No caso de Belo Horizonte, Carrieri (2012) já enfatizou essa migração do que chama de classe dominante ou elite para outros centros urbanos como os shoppings centers. Ainda que o centro tradicional possa acumular nele algumas atividades essenciais, a exemplo dos serviços públicos, as demais ofertas de bens e serviços agora se encontram também em outros centros, o que reduz a necessidade de grupos sociais economicamente favorecidos frequentarem esse centro tradicional.

Essa mediação entre os indivíduos e os usos e apropriações do espaço urbano social caracteriza os shoppings centers como espaços organizacionais (Figueiredo \& Cavedon, 2012), especialmente por sua intervenção socioeconômica na produção do espaço das cidades. Por serem construções sóciohistóricas, os shoppings centers refletem dinâmicas sociais amplas, podendo, então, reproduzir práticas de segregação e de discriminação da sociedade. É essa característica de processo organizativo dos shoppings centers no espaço urbano que pode alterar a estrutura socioeconômica existente nas cidades, ao deslocar centralidades de atividades comerciais e de serviços (Alves, 2011), bem como difundir práticas segregatórias entre diversos grupos sociais ao confrontar diferentes modos de vida dos indivíduos em um mesmo espaço social (Figueiredo \& Cavedon, 2012), seja esse confronto expresso pela dimensão material das organizações incorporada nos indivíduos (Flores-Pereira, Davel, \& Cavedon, 2008), seja por suas manifestações simbólicas de preconceito, por exemplo, na produção de discursos que justificam a discriminação racial (Pereira, Torres, \& Almeida, 2003).

Argumentamos que esse movimento dos shoppings como espaços de segregação socioespacial no contexto urbano tem relação com os discursos sobre as relações raciais no Brasil e, mais especificamente, com o discutido preconceito de marca justamente por ser esse um preconceito que considera outros aspectos associadas à cor da pele: o lugar e a posição sociais ocupados pelo sujeito, os espaços que constituem seus territórios, a maneira como se vestem ou se comportam, dentre outros aspectos. E é no intuito de discutir essa relação que apresentamos os dispositivos metodológicos que utilizamos para a seleção do corpus discursivo a ser analisado.

\section{Caminhos Metodológicos}

Trabalhamos neste artigo com a noção de discursos que são tidos como textos em um contexto sócio-histórico que configuram as instâncias da linguagem em que os processos ideológicos são articulados com fenômenos linguísticos (Dijk, 1997). Empregaremos neste artigo de abordagem 
qualitativa o método da Análise do Discurso (AD), a qual envolve uma análise das condições de produção dos enunciados (Orlandi, 2009). Nossas bases teóricas para a realização da AD são uma combinação das concepções de diversos autores sobre o discurso, tais como Pêcheux e Fuchs (1997) e Maingueneau (2006). Empregamos uma AD de corrente francesa, pois temos como focos analíticos a análise lexical, a análise de temas e figuras explícitos e implícitos, de personagens, de aspectos interdiscursivos, de processos de reflexão e de refração, as já mencionadas condições sociais de produção dos discursos, as análises dos discursos presentes, e dos aspectos ideológicos defendidos e combatidos nesses discursos (Faria, 2009).

Analisaremos basicamente os elementos explícitos e implícitos dos discursos, os silenciamentos (não só o dito, mas também o não dito) e as formações ideológicas presentes, entendendo que as formações ideológicas estão envolvidas com as posições sociais dos sujeitos (Pêcheux \& Fuchs, 1997). Este artigo traz para discussão a temática da segregação socioespacial. E os discursos, para Faria (2009), envolvem também elementos espaciais e geográficos. Nesse sentido, os aspectos espaciais contidos nos discursos também serão analisados, sobretudo porque dizem respeito aos usos sociais de shopping centers que se localizam em espaços diversos na cidade de Belo Horizonte.

O corpus de análise é constituído por discursos presentes na rede social Facebook, tendo sido então a pesquisa documental o método de coleta de dados utilizado. Esses discursos se referem a uma imagem que foi veiculada em um portal de notícias sobre a cidade de Belo Horizonte que está hospedado em uma página do Facebook que pode ser curtida por qualquer usuário, tornando suas publicações de caráter público. A imagem foi publicada no Portal com uma hashtag que a caracterizava: \#Humor. A imagem foi construída por um dos seguidores dessa página e, por não termos solicitado autorização para sua divulgação, ela não será incluída neste artigo, tendo sido o seu conteúdo explicado na Introdução. O corpus de análise deste artigo tem como foco os discursos que foram postados em resposta a essa imagem, dada a popularidade que ela adquiriu (foram analisados 394 comentários, apenas aqueles que foram postados diretamente na página do portal, sem considerar os comentários das páginas de quem compartilhou a imagem, já que não acessamos páginas de perfis individuais para a coleta desses dados, apenas a página do portal. Essa informação é importante porque significa que o número real de comentários extrapola os 394$)^{(4)}$.

Como os discursos analisados se referem a processos dialógicos, sendo diálogos entre usuários do Facebook, consideraremos também nas análises a dimensão relacional dos discursos (Gergen, Gergen, \& Barret, 2004). Considerando essa dimensão, destacamos que os enunciados foram produzidos e publicados não só como uma manifestação de resposta direta à imagem que foi publicada, como também de resposta a outros enunciados que já haviam sido feitos por outros usuários, havendo no espaço virtual constituído pelo Facebook o estabelecimento de processos interacionais e dialógicos por meio dos enunciados e também pelas condições de produção desses enunciados, que são as enunciações.

Os enunciados compreendem o que é literalmente dito ou escrito (Faria, 2009). A enunciação é o processo que constitui o enunciado. É como se a enunciação fosse o processo, e o enunciado, o seu produto (Faria, 2009). Enquanto o enunciado pode ser repetido, a enunciação não, pois ela é um acontecimento único, estando localizada em um determinado tempo e espaço (Maingueneau, 2006). E é sendo constituído pelas noções de enunciado e de enunciação que os discursos serão entendidos neste artigo.

\section{Minas, Del Rey, Estação e Via Shopping: "É Shopping de Preto, de Favelado, mas como Eles Assaltam, Ninguém Fica no Retrato"}

Parodiando uma música brasileira de funk ${ }^{(5)}$, que diz, "é som de preto, de favelado, mas quando toca, ninguém fica parado" (Amilcka \& Chocolate, 2006, faixa 19), os discursos dos usuários do Facebook que comentam a imagem veiculada e que dialogam sobre o público que frequenta os shoppings belo-horizontinos trazem hegemonicamente a ideia de que quatro shoppings da cidade são 
shoppings de preto, de favelado. São os seguintes shoppings: Minas Shopping, Shopping Del Rey, Shopping Estação e Via Shopping. Dentre esses, a imagem veiculada aborda explicitamente apenas o Minas Shopping. No entanto, os discursos dos usuários estendem a esses outros shoppings mencionados o perfil do usuário que é representado por um jovem negro de boné, brincos, piercing e camiseta. Em primeiro lugar, há um questionamento dialógico a respeito de qual personagem frequentaria esses outros shoppings: "O delrey?? Falto os favela do delrey asuhaushshua" (Camila, 2013); "Faltou o Estação e o Del Rey” (Ricardo, 2013); "Ah tem que incluir o Estação e o Del Rey. Mas a tradução desses aí com imagens, ficou perfeita" (Danilo, 2013). A esses questionamentos, os usuários respondem por meio de um discurso de similaridade dos grupos que frequentam alguns desses shoppings: "DELrey = Minas" (Vanessa, 2013), "O Estação Bh é igual ao Minas.... kkkkkk" (João, 2013), "Dey Rei e Minas podem dividir a mesma foto" (Mateus, 2013).

Sendo considerados explicitamente como shoppings que possuem o mesmo perfil de usuário construído pelo discurso imagético que traz a foto de um jovem negro, os enunciados constroem discursivamente a personagem dos negros como estando associados à favela, conforme pode ser observado na Tabela 1. Essa consideração reflete que, nas favelas brasileiras, a maioria dos moradores é negra (Imas \& Weston, 2012), mas ao mesmo tempo refrata a associação negro = favelado, generalizando-a.

Tabela 1

\section{Elementos Léxicos de Associação do Negro à Favela}

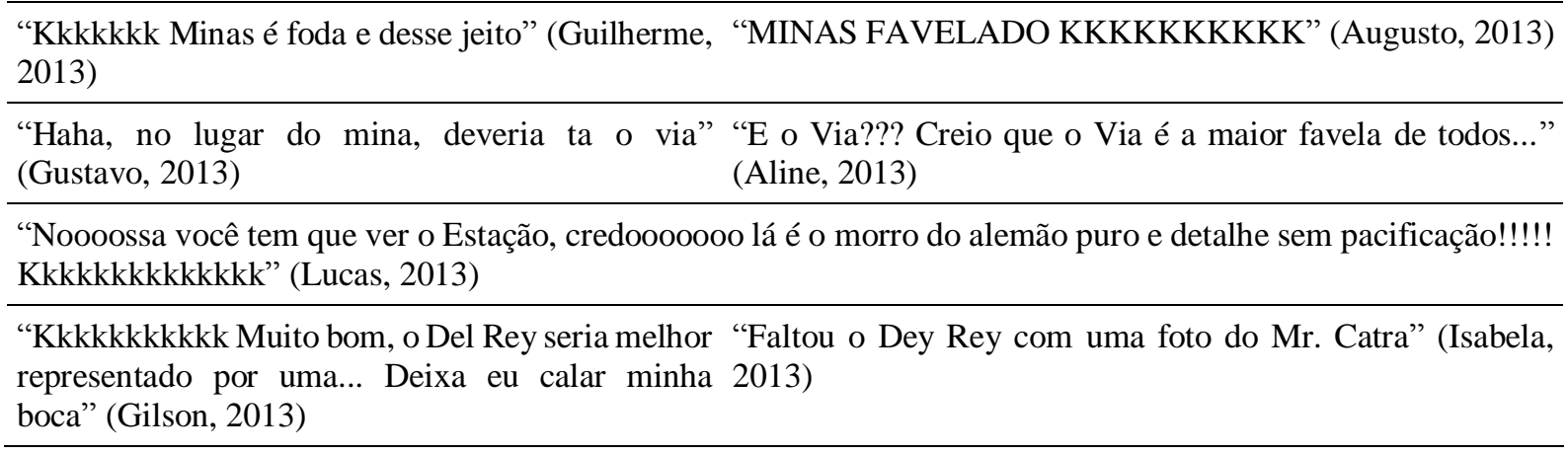

Como se pode observar nos enunciados, os léxicos favela, favelado são empregados de modo a lhes conferir tanto explícita quanto implicitamente um sentido pejorativo (dependendo do enunciado). Além da já comentada associação negro = favelado (como no enunciado que, em resposta à imagem do jovem negro, se diz "MINAS FAVELADO KKKK" (Augusto, 2013), constrói-se a personagem do negro como sendo o mano e como aquele que se associa ao funk, como implicitamente se considera no enunciado: "Faltou o Del Rey com uma foto do Mr. Catra" (Isabela, 2013), um cantor brasileiro de funk que é também negro.

Além disso, o frequentador desses shoppings é caracterizado por uma postura marrenta, a qual é representada pelos léxicos sou phoda ou sou foda: "O minas é favela geral! Só vejo 'sou foda' La!!!!" (Fernando, 2013); "Sou Fhoda. Kkkk" (Larissa, 2013). Essa caracterização do negro mano como aquele que se acha foda guarda relações com o que Moura (2012) observou em relação ao uso dos shoppings como espaços de sociabilidade e de lazer por jovens da periferia de Salvador. Em um estudo etnográfico, a autora observou que os shoppings produzem certo constrangimento a esses jovens em determinadas áreas internas, mas são, ao mesmo tempo, um de seus espaços favoritos de lazer. Ela afirma que "é curiosamente em shopping, local de valorização do consumo e da aparência física, que os jovens de periferia vivenciam o lazer e se sentem acolhidos. É nessa 'pequena cidade' que os jovens se identificam e gostam de "curtir a vida"” (Moura, 2012, p. 6). A autora coloca inclusive no título de seu trabalho a expressão no shopping nóis é patrão!, evidenciando uma postura percebida na relação de alguns jovens com o espaço do shopping. Tal postura se relaciona justamente com essa característica sou phoda ou sou foda. 
Retornando à análise dos discursos, há enunciados construídos no sentido de trazer implícitos subentendidos, tal como "Kkkkkkkkkkk Muito bom, o Del Rey seria melhor representado por uma... Deixa calar minha boca" (Gilson, 2013). O subentendido nos permite apenas uma associação direta do usuário do Shopping Del Rey a algo pejorativo, embora não se possa desvelar qual é a real associação que o enunciatário pretendeu fazer. Em alguns casos, a associação do negro = favelado também se faz presente por meio da invocação de um exemplo espacial que se refere a uma favela carioca: "Noooossa você tem que ver o Estação, credooooooo lá é o morro do alemão puro e detalhe sem pacificação!!!!! Kkkkkkkkkkkkkk" (Lucas, 2013). Ao construírem uma identidade negativa para os negros, os enunciados refletem um preconceito que é característico das relações raciais brasileiras. Esse preconceito é ainda caracterizado por outro aspecto importante que pode ser observado nos próximos enunciados $($ o negro $=$ criminoso), conforme pode ser observado na Tabela 2, os quais explicam o restante da nossa paródia: mas como assaltam, ninguém fica no retrato.

Tabela 2

\section{Léxicos de Associação dos Negros com a Criminalidade}

"Faltou o delrey, mas o personagem dele ta preso. Delrey e minas formam uma quadrilha de assaltante!!!!" (Adriano, 2013).

“Kkkkkkkkkkkkkkkkkkk Acho isso uma puta falta de sacanagem!!!!!! É pq a galera do Del Rey não pode aparecer em redes sociais, alguns s ao procurados pela policia, sabe como que é né.” (Natalia, 2013).

"Iam postar a foto do Del Rey mas o povo que freqüenta roubou a foto já” (Miguel, 2013).

"Eles iam colocar o Del Rei ai tbm, mas o personagem da foto tava assaltando o casalzinho do Diamond." (André, 2013).

Humoristicamente, os enunciados explicam a ausência do Shopping Del Rey na imagem, alegando que seus frequentadores estão presos ou são procurados pela polícia. Trata-se da mencionada associação do negro à criminalidade (Pereira et al., 2003), o que se revela por meio de escolhas lexicais como preso, quadrilha de assaltante, procurados pela polícia e assaltando. Esse discurso se associa a um discurso hegemônico na sociedade, o qual muitas vezes se mantém no nível do implícito ou do não dito. Entretanto, no caso dos enunciados aqui mencionados, a associação está explícita.

São discursos que refletem como a cor é socialmente construída (Barros, 2009). O negro apresentado na imagem em associação ao Minas Shopping simboliza o negro que é especificamente favelado, mano e ainda criminoso. Há também estratégias de criação de interdiscursividades entre os grupos sociais que frequentam cada um dos shoppings, como no caso do enunciado que opõe o usuário do Del Rey ao usuário do Diamond Mall: "Eles iam colocar o Del Rei ai tbm, mas o personagem da foto tava assaltando o casalzinho do Diamond" (André, 2013). Nessa interdiscursividade, a criminalidade aparece associada aos favela do Del Rey e não ao casal sofisticado do Diamond Mall. Sendo os shoppings espaços que trazem consigo elementos de segregação socioespacial, tendo sido construídos inicialmente como espaços direcionados para os grupos sociais com maior poder aquisitivo, os discursos revelam uma reação desses moradores da cidade de $\mathrm{BH}$ ao que metaforicamente podemos chamar de invasão do morro ao shopping, tanto que os shoppings discursivamente associados à imagem do jovem negro são inclusive descaracterizados como tal: "O Del Rey deixou de ser shopping" (Antonia, 2013); “O Del Rey, coitado!" (Antonio, 2013); "Dels é tão inútil que nem ta no post” (Rebeca, 2013).

A despeito de ser atualmente um shopping com grande circulação de pessoas, localizado inclusive próximo à Universidade Federal de Minas Gerais, o Shopping Del Rey é discursivamente construído como um shopping inútil. Analisando os processos dialógicos construídos pelos comentários, essa inutilidade está implicitamente contraposta ao que tradicionalmente se considera como shopping center estritamente em virtude do seu perfil de frequentadores, não havendo menção a nenhum aspecto qualquer que difira desse. Nesse sentido, o shopping center frequentado por um público que simbolicamente não pertence a esse lugar seria simbolicamente descaracterizado como tal. Essa descaracterização fica ainda mais evidente quando um usuário adverte, em relação à imagem do jovem

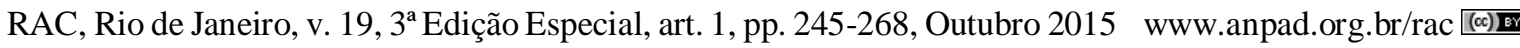


negro, que "O melhor vcs esqueceu o shopping oi!!!!!” (Rafael, 2013). Ele se refere ao Shopping Oiapoque, um shopping popular da cidade de BH que é localizado no entorno da rodoviária, região do centro tradicional da cidade, que hoje assume características de espaços populares marcados por um número expressivo de vendedores ambulantes e de pessoas circulando. Esse processo discursivo de descaracterização do shopping center, marcado pela ironia em um contexto de humor (o enunciador escolhe o léxico melhor em sentido irônico, pois não quis dar um sentido denotativo a melhor como se o Shopping Oi fosse de fato o melhor, mas sim o que mais cabia ao humor que se estava empregando no momento para se falar dos shopping centers da cidade) pode ser compreendido em termos contextuais pelo o que L. M. Andrade (2012) observa a respeito dos shopping latino-americanos: há a reprodução de discursos que demarcam não só classes sociais, mas também níveis de civilização. O shopping entendido como símbolo de civilização apresenta, no caso aqui analisado, uma prerrogativa implícita de ser frequentado por apenas alguns grupos sociais. Aqueles que destoam dos grupos sociais esperados são discursivamente descaracterizados.

Diante desses discursos de estereotipação, alguns usuários se defendem por frequentarem os shoppings que são descaracterizados como tal, demonstrando uma incorporação do baixo status simbólico desses shoppings na dinâmica de segregação urbana da cidade: "P.!(6) Eu toh no Minas, TRABALHANDO! Kkkk" (Daniele, 2013); "PERFEITOOO...Ainda bem q não falaram do Del Rey q é o q eu mais frequeno por ser perto daki de Ksa..." (Eduarda, 2013). Ambos os enunciatários se justificam por frequentar os dois shoppings mais desqualificados por questões de funcionalidade (o trabalho) ou de circunstância (proximidade da casa).

A estereotipação da personagem do negro favelado fica ainda mais evidente quando uma usuária diferencia essa personagem do negro xiquetérrimo: "mas há milhares de negros xiquetérrimo que vão em lugares muitíssimo mais xiques que o barango do shopping diamond e brancos uó que vão no minas ou que nem vão em shopping sei lá. Eu me identifico como parda e detesto shopping" (Fernanda, 2013). Mesmo em um enunciado que critica a imagem veiculada, há uma reprodução dos estereótipos. O enunciado nos remete ainda à histórica expressão negro escovado, que diz respeito ao negro arrumado que, socialmente, poderia ser mais bem visto. Além disso, o enunciado invoca a discutida figura do mestiço (Correa, 1996; Sansone, 1996) em nossa sociedade. Identificando-se como parda, a enunciatária se diferencia dos negros. Os discursos se associam à dinâmica de segregação urbana da cidade não só em virtude dos aspectos históricos de segregação das cidades já discutidos, mas também porque os shoppings que são descaracterizados como shoppings tradicionais em virtude do público que os frequenta (embora tenham todas as características tradicionais de shopping centers) estão localizados mais na região norte da cidade, que é relativamente desvalorizada em relação à região Sul, habitada por grupos sociais de maior poder aquisitivo.

\section{A Confirmação das Outras Dimensões de Segregação: É Shopping de Homossexual, de Gente Bonita, de Nerd...}

Embora os discursos de cunho racial sejam os mais encontrados nos enunciados que comentam a imagem, há também a confirmação discursiva de outras dimensões de segregação socioespacial. Embora sejam dimensões ainda não tão demarcadas socialmente como as que se referem à classe social e à raça (as que acabamos de discutir), trazem aspectos importantes para se pensar com que cor eu vou ao shopping que você me convidou. Nesse sentido, a cor à qual nos referimos assume outros sentidos que extrapolam a ênfase que os enunciados analisados acabam dando à cor socialmente construída como negra. Embora esse seja o principal foco dos resultados deste artigo, em virtude dessa maior ênfase, este tópico nos traz outros elementos que são importantes.

Os demais shoppings mencionados na imagem e também pelos usuários não são caracterizados por uma personagem negra e nem associados à favela ou à criminalidade. O Shopping Cidade, associado a uma imagem das cantoras Ana Carolina e Maria Gadu é discursivamente criado como o shopping dos homossexuais, permanecendo no não dito outras características como, por exemplo, a que classes sociais 
pertencem ou não. Há nessa construção tanto um possível reflexo da maior frequência de homossexuais assumidos nesses shoppings em relação aos demais como também uma refração, já que o shopping é unicamente caracterizado, em todos os enunciados que o mencionam, pelas personagens dos homossexuais, deixando de considerar outros grupos que possam lhe frequentar.

A construção da figura do shopping dos homossexuais traz um incômodo aos usuários: "O shopping cidade esta assim mesmo, nada contra mas explicar pra uma criança de 7 anos por que duas pessoas do mesmo sexo estão se beijando e muito difícil" (Letícia, 2013). Esse incômodo reforça o que os estudos sobre segregação socioespacial discutem: a busca pela convivência entre os iguais. Nesse caso específico, entre os heterossexuais. Sendo assim, aqueles que se incomodam com as manifestações explícitas de contato entre casais homossexuais tendem a evitar o Shopping Cidade. Mesmo que a literatura indique que os iguais que dividem uma determinada localização espacial não necessariamente criem vínculos afetivos (L. T. Andrade, 2002), eles podem buscar manter essa ideia de grupo homogêneo pela sensação de segurança e de status social que ela pode invocar.

BH Shopping e Diamond Mall são os shoppings mais valorizados na construção dos discursos: "O Bh é o que mais tem gente bonita" (Carolina, 2013); "Chic demais o diamond, hein?" (Lorena, 2013). A construção discursiva do Diamond Mall como o shopping de pessoas que se vestem sofisticadamente traz também implícitos de que quem não estaria bem vestido não seria ali bem aceito: "Uma vez fui no Diamond e fiquei com medo de me expulsarem achando que era um mendigo" (Paulo, 2013). Ambos os shoppings são localizados na região sul (ou centro-sul) da cidade, sendo o BH Shopping localizado em um dos bairros mais valorizados.

O Pátio Savassi, localizado em um dos bairros mais valorizados da cidade, o bairro Savassi ${ }^{(7)}$, é curiosamente pouco mencionado nos enunciados discursivos. Em relação a ele, há unicamente uma confirmação da associação com a imagem dos rapazes jovens que se vestem com roupas coloridas, associação que se amplia ainda às chamadas patricinhas: "O Pátio tem tudo a ver... so faltaram as Patys!!!" (Laís, 2013). Em termos de condições sociais de produção dos discursos, atribuímos a pouca menção a esse shopping localizado em uma região privilegiada por ele ser discursivamente construído como apresentando um conceito diferente dos outros shoppings da cidade:

Primeiro Lifestyle Center ${ }^{(8)}$ de Belo Horizonte, o Pátio Savassi é especial e diferente. Eclético, reúne com elegância marcas de sucesso internacional a simpáticas sorveterias e cafés. Construído em um dos pontos de maior efervescência cultural da cidade, no coração da Savassi, o Pátio reflete, em seu projeto arquitetônico, o conceito de um lifestyle, no qual os corredores se confundem com as ruas do bairro, dentro de uma proposta agradável, que oferece, além de conforto, segurança (Pátio Savassi, n.d.).

O conceito apresentado acaba não atraindo uma diversidade considerável de grupos sociais. Segundo P. S. Nogueira (2010), o Pátio Savassi invoca um imaginário de sofisticação e, apesar de não contar somente com lojas mais caras, tendo também lojas mais populares, acaba afastando alguns grupos mesmo que esses tenham poder aquisitivo para frequentá-lo.

Pátio Savassi é um shopping center da zona sul de Belo Horizonte. Suas lojas variam de caras a mais populares, como as Lojas Americanas, por exemplo. O fato de Laura [sujeito de uma pesquisa sobre práticas de arquitetura para demandas populares] não comprar seus sapatos nesse shopping não decorre diretamente de seu poder aquisitivo, mas do imaginário de sofisticação que, aos seus olhos, cerca o lugar. Não lhe parece natural frequentá-lo (P. S. Nogueira, 2010, p. 30-31).

Além disso, nossa observação enquanto autores deste artigo e observadores do campo estudado é que, mesmo dentre grupos econômica e socialmente mais favorecidos, sua atração se restringe significativamente àqueles que moram em suas proximidades. Nessa dinâmica, o BH Shopping acabou se constituindo como um shopping mais atrativo para esses grupos. Além de ser localizado no Belvedere, bairro muito valorizado, é um shopping tradicional, mas que reúne marcas importantes dentro do cenário internacional de consumo. 
Depois do Minas Shopping e do Shopping Del Rey, o shopping mais mencionado nos enunciados é o Boulevard Shopping. Alguns concordam com sua associação à imagem de um deserto, mas a maioria o defende: "O Boulevard não é desse jeito não" (Andréa, 2013); "Só não concordei com boulevard" (Tatiana, 2013); "Discordo! O Boulevard nem é assim" (Maria, 2013). Outros o consideram como um dos melhores shoppings da cidade justamente por ser mais vazio: "O Boulevard é o melhor, $\mathrm{n}$ tem nada pior q shopping cheio" (Alice, 2013); "Por isso só vou ao Boulevard!" (Paola, 2013); "Desse modelo...por isso q eu gosto do boulevard! \#antisocial" (Clarissa, 2013). Esses enunciados refletem o que teoricamente discutimos como sendo a construção do shopping center como um elemento de segregação no espaço urbano e também como um espaço para conferir sensação de conforto e de segurança aos seus frequentadores. E tanto essa segurança quanto o conforto são ameaçados quando se tem shoppings lotados, causando insatisfação aos usuários que comentam a imagem: "Boulevard ta ficando lotado e eu acho isso péssimo" (Luísa, 2013).

A confirmação discursiva da segregação está também presente nos discursos quando os usuários incorporam as associações da imagem veiculada e se classificam de acordo com os shoppings: "Eu sou nerd, por isso só vou no Bh" (Flavia, 2013). Essa classificação, no entanto, só ocorre de maneira explícita e sem justificativa quando se refere aos shoppings mais valorizados nos discursos (BH Shopping, Diamond Mall e Boulevard). Como vimos no item anterior, há justificativas de usuários para frequentar aqueles que são mais desvalorizados (os shoppings dos favelados). No entanto, para se afirmarem frequentadores dos melhores shoppings, não há justificativas: "Sou 100\% Diamond mall" (Amanda, 2013); "Achei muitíssimo engraçado eu vou no Bh" (Cristina, 2013); "Desculpa ai...mas eu só frequento o Diamond" (Marcelo, 2013). Há um único enunciatário que se classifica como usuário de um shopping que é desvalorizado nos discursos, sem apresentar justificativas: "Kkkkkkkk eu sou tipo minas" (Julia, 2013). Ao fazê-lo, ele identifica-se implicitamente com a imagem do jovem negro (que é favelado e mano).

\section{Preconceito? Não! 'É Apenas a Nossa Sociedade Dividida”!}

Pouquíssimos usuários consideraram a imagem e os discursos a ela veiculados como uma manifestação de preconceito, isso porque ela é curtida, compartilhada e comentada, sobretudo por quem concorda com suas associações. Além de ter sido publicada com a hashtag \#Humor, assim ela é interpretada pela quase totalidade dos enunciados. Sua popularidade se deveu justamente a essa interpretação, a qual se expressa, entre outros aspectos, pela expressiva escolha lexical de expressões que, na linguagem coloquial cibernética, indicam risos ou gargalhadas, a exemplo de: "Kkkkkkkk.... é bem assim!!!" (Mariana, 2013), "Rachei de rir. Heheheh” (Laura, 2013), "Kkkkkkk adorei!!!!!” (Carina, 2013) ou "Gostei do minas...kkkk" (Marina, 2013).

Para Cavedon e Stefanowski (2008), o ato de rir pode assumir vários significados. E análise dos discursos de acordo com seu contexto sócio-histórico de produção é importante porque, para as autoras, o humor envolve um compartilhar de sentidos que pode não ser compreensível em outros contextos. A divisão que se faz hoje em relação ao perfil de frequentador de cada shopping pode não fazer sentido daqui a alguns anos. Os discursos que afirmam o preconceito enfatizam que a imagem e as manifestações discursivas a ela relacionadas não são simples brincadeiras, mas sim uma manifestação de preconceito e discriminação, como pode ser observado na Tabela 3. 
Tabela 3

\title{
Enunciados sobre o Humor como Forma de Discriminação
}

\begin{abstract}
"É engraçado como as pessoas acabam demonstrando mesmo o mito da democracia racial no Brasil. Curtem, compartilham e comentam uma publicação dessa que, somente para dizer uma das características, demonstra o racismo que fica escondido na nossa sociedade." (Vitoria, 2013)
\end{abstract}

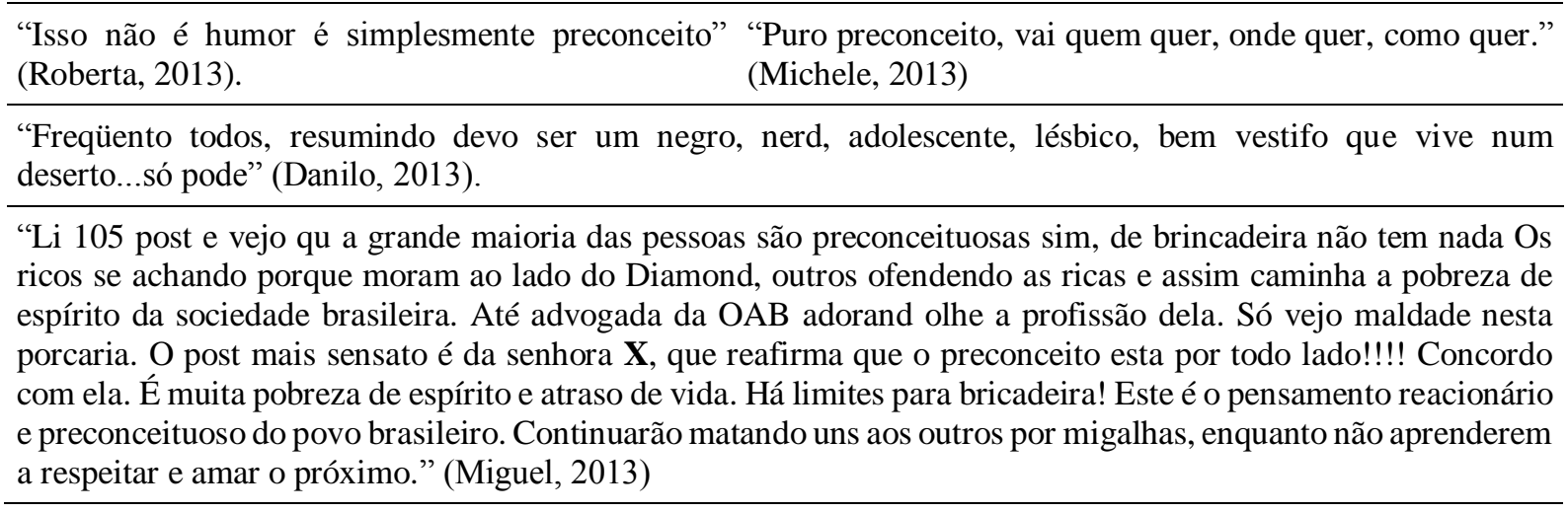

Esses enunciados trazem para o nível do explícito o aspecto da segregação, caracterizando os discursos como preconceituosos e racistas. Do nosso referencial teórico, é mencionado em um dos enunciados o mito da democracia racial (Freyre, 1961), o qual reflete um contexto social de produção dos discursos analisados, que é o de serem produzidos em um país que tende a ver velados os discursos preconceituosos. A partir da interação dialógica criada por meio dos discursos, a maioria dos usuários rechaça os enunciatários que acusam o preconceito, o que novamente nos remete a essas mitificações relacionadas à inexistência do preconceito. Como o preconceito no contexto social brasileiro é hegemonicamente de marca (O. Nogueira, 2007), ele assume variações e relatividades que dependem de seu contexto de análise, o que pode acabar contribuindo para a falsa sensação de que ele não existe.

Justificando-se pelo discurso do humor ("brincadeira" (Eva, 2013), "levar na esportiva" (Felipe, 2013), "não sabe brincar, não desce pro play" (Rodrigo, 2013), "humor!!!" (Fernando, 2013)), os enunciados apresentados negam a existência do preconceito. Essa negação traz um tipo de associação que é comum em nossa sociedade: humor e preconceito, sendo o último revestido pelo primeiro. $\mathrm{O}$ humor atrelado ao preconceito já vem sendo alvo de alguns estudos organizacionais, como os de Irigaray, Saraiva e Carrieri (2010) e Furtado, Carrieri e Bretas (2011). Para os primeiros autores, "o humor se destaca como forma de comunicar algo, mesmo que não explícito, aparando arestas e suavizando críticas e agressões, sob o pretexto de provocar o riso" (Irigaray, Saraiva, \& Carrieri, 2010, p. 891).

Em relação a esses enunciados que negam o preconceito, seus enunciatários pronunciam-se de maneira categórica dentro de um esforço discursivo para chamar a atenção daqueles que os acusaram de preconceituosos, utilizando léxicos que refletem uma postura impositiva: "povinho babaca e fresco viu, p. que p.!" (Valter, 2013); "É brincadeira p." (Roberto, 2013), e também pelo excesso de pontos de exclamação: "Ninguém leu a legenda: humor!!!” (Tiago, 2013). Um dos enunciados minimiza tanto o discurso do preconceito quanto o discurso da segregação socioespacial: "Não vejo nada apelativo ae [respondendo a quem acusou o preconceito] apenas a nossa sociedade dividida [apenas a segregação]" (Daiane, 2013). A escolha do léxico apenas minimiza a importância da discussão a respeito de se ter uma sociedade dividida, divisão essa que acaba sendo naturalizada e não questionada. 


\section{Considerações Finais}

Os discursos analisados demonstraram a construção do shopping center como uma área dura, específica, em que a cor afeta a permissão simbólica para determinados grupos sociais e, sobretudo, são espaços de denotações e conotações hierárquicas, espaços simbólicos de segregação socioespacial, em que a personagem do jovem negro, mano, favelado e que gosta de funk é implicitamente negada como personagem comum a um shopping center.

Por esse motivo, ir com a cor negra (entendendo a cor como uma construção social e não meramente a cor da pele) a um shopping pode assumir basicamente dois sentidos sociais, de acordo com os discursos analisados. Ir com a cor negra pode primeiro significar ser favelado, mano e sou phoda, ser o usuário que frequenta os shoppings distantes da zona sul da cidade. Significa frequentar aquilo que simbolicamente deixou de ser um shopping center. Uma expressão comum no Rio de Janeiro para se referir ao funk é que o morro invadiu o asfalto (Meneguello \& Amoroso, 2006). Nos discursos aqui analisados, pode-se dizer que o morro invadiu o shopping center de BH. Mas não é um morro qualquer, de gente honesta ou de trabalhadores, é o morro do Alemão, não pacificado ainda. Os negros não são só favelados, são também criminosos. Representam um risco ao shopping center como fenômeno social idealizado, como instrumento de segregação socioespacial nos espaços urbanos.

O segundo sentido é que os negros também podem ir a outros shoppings. Mas são os negros xiquetérrimo(s), os negros escovados. Pode-se ir com a cor negra a outros shoppings, mas uma cor negra associada a outros elementos visuais não característicos da personagem do negro favelado. Essa relativização é justamente característica do preconceito de marca brasileiro (O. Nogueira, 2007), o qual se associa a outras dimensões para além do aspecto racial. Para os outros shoppings, fica o colorido. Tanto o colorido metonimicamente associado aos indivíduos que possuem outras cores de pele (em relação à cor da pele, não falamos aqui explicitamente de outras cores porque houve uma ênfase discursiva apenas à cor negra, pois não houve diferenciações explícitas em relação à cor da pele das demais personagens presentes nas outras imagens), outras cores socialmente construídas, como também aqueles que se vestem de colorido, aqueles que são mauricinhos, patricinhas e os que simbolizam um arco-íris de cores: os homossexuais.

Com que cor eu vou pro shopping (de $\mathrm{BH}$ ) que você me convidou? A cor é aqui entendida como um aspecto que extrapola um simbolismo ligado às relações raciais em nosso país, a cor ganha outras dimensões, outras facetas. O negro é discursivamente estereotipado, oriundo de espaços socialmente demarcados (as favelas), com práticas sociais peculiares (o modo de se vestir, o gosto musical) e com um caráter diferente daqueles que frequentam, por exemplo, o Diamond Mall, eles assaltam aqueles que frequentam o Diamond Mall. Os discursos analisados trazem não só uma ideia de rompimento com o que seria o tipo ideal do shopping center, de um rompimento com os ideais de segregação nos espaços urbanos, mas também refletem processos sociais de reprodução dessa segregação nos espaços organizacionais. O shopping é um espaço organizacional que pode introduzir novas separações às separações já existentes, sobretudo reforçando-as, introduzindo microsseparações que refletem separações maiores.

Os resultados demonstram o sentido simbólico do shopping como espaço de segregação social, que implicitamente deveria ser restrito a apenas determinada parcela da sociedade para ser considerado um espaço valorizado, seguro e que conferiria distinção social. Os discursos se alinham então aos discursos hegemônicos que estão vinculados ao próprio surgimento dos shoppings, como vimos na discussão teórica que fizemos. Além disso, demonstra como se criam novos guetos, criam-se novos processos de segregação dentro da própria segregação. Nesse sentido, o presente estudo contribui para o campo dos estudos organizacionais por ampliar o sentido simbólico que se atribui ao espaço organizacional do shopping center, demonstrando como as dinâmicas espaciais que ocorrem em seu território refletem dinâmicas maiores. Além disso, invocamos aqui, assim como já fizeram Rosa (2012), Nkomo (2011) e Conceição (2009), a necessidade de que os estudos organizacionais se voltem para as discussões raciais, introduzindo para seus debates a construção social da cor e a maneira como essa 
construção está refletida nos espaços organizacionais e urbanos. Contribuímos para reflexões a respeito da articulação da ideia de organização entendida como espaço social com as noções que se vinculam a dimensões raciais e sociais da vida urbana.

Outra contribuição do estudo é dar continuidade à problematização que alguns autores desse campo de pesquisa já fizeram em relação ao humor. E as análises deste artigo trazem uma abordagem complementar a duas linhas de pesquisa sobre humor que têm sido encontradas na Administração. De acordo com Carrieri (2004), estuda-se o humor por uma vertente funcionalista como uma ferramenta de controle gerencial que pode abrandar a maneira de comunicar esse controle; e também por outra vertente que enfatiza o humor como estratégia de resistência de trabalhadores. No caso aqui analisado, não há um humor que se relaciona à organização na figura dos gestores e nem dos trabalhadores. Há um humor advindo de frequentadores de um espaço organizacional, dos seus próprios clientes e usuários que acabam por conceder uma espécie de controle simbólico em relação a quem frequenta ou não determinados espaços. Trata-se de uma dinâmica de segregação de quem frequenta e de quem deveria frequentar os shoppings por meio de estereotipações.

Pretendemos para estudos futuros dar vozes a mais sujeitos que podem falar sobre o espaço do shopping center, como seus administradores, lojistas, trabalhadores e seguranças. Esses sujeitos podem trazer elementos importantes para o entendimento do shopping como área dura, revelando a maneira como percebem os grupos sociais que frequentam esses espaços. Os administradores podem, por exemplo, revelar se atender aos grupos sociais economicamente inferiores em relação aos que tradicionalmente frequentariam os shoppings é uma orientação de mercado deliberada ou não. Ou seja, se a invasão do morro ao shopping center de BH é entendida como invasão apenas em um sentido simbólico ou não.

\section{Notas}

${ }^{1}$ Facebook é uma rede social virtual gratuita fundada no ano de 2004 nos Estados Unidos da América por Mark Zuckerberg.

${ }^{2}$ Hashtagh é uma expressão de língua inglesa utilizada para designar o assunto ou tema que está sendo discutido nas redes sociais virtuais. As hashtaghs são sempre precedidas pelo símbolo \#.

${ }^{3}$ Curtir é um dispositivo utilizado na rede social virtual Facebook para indicar a aprovação de uma postagem na rede sem a necessidade de realizar algum tipo de comentário na mesma.

${ }^{4}$ Utilizamos nomes fictícios para identificação dos comentários do post analisado a fim de evitar uma identificação direta e imediata dos sujeitos que são os enunciadores dos discursos

${ }^{5}$ Facina, A. (2009, maio). "Não me bate Doutor": funk e criminalização da pobreza. Anais do Encontro de Estudos Multidisciplinares em Cultura. Salvador, BA, Brasil, 5, retomando as discussões de Hermano Vianna sobre o mundo do Funk Carioca, considera o Funk como um gênero musical criado pelos negros nos Estados Unidos da América, que no Brasil foi articulado com tradições musicais afrodescendentes produzindo uma releitura de um tipo de música ligado à diáspora negra no continente americano.

${ }^{6}$ Optamos por abreviar os palavrões nos textos reproduzidos, mas mantendo sua indicação por estarmos trabalhando com os comentários dos próprios sujeitos e priorizarmos a maneira como eles foram escritos. Assim, mesmo que o leitor não se depare com a apresentação explícita dos palavrões, saberá que as abreviações os constituem de acordo com os comentários originais desses sujeitos.

${ }^{7} \mathrm{O}$ bairro Savassi simbolicamente se constituiu como um bairro charmoso da cidade. Está localizado na região Centro-Sul e é conhecido pela grande quantidade de bares que possui. Segundo o site da prefeitura da cidade de Belo Horizonte, o bairro "se destaca como um dos mais bem sucedidos pólos econômicos e culturais da cidade, com um comércio variado, além de shoppings como o Pátio Savassi .... Ostenta lojas de grifes famosas e ateliês, sempre prontas a surpreender as passarelas com o que há de mais arrojado e eclético" (Prefeitura Municipal de Belo Horizonte. (2007). Badalação e charme na região CentroSul. Belo Horizonte: Autor. Recuperado de http://portalpbh.pbh.gov.br/pbh/ecp/contents.do?evento=conteudo\&idConteudo=23747\&chPlc=23747\&\&pIdPlc=\&app=sala noticias) ATENÇÃO: polos

${ }^{8}$ Lifestyle center _é um conceito de produção de um espaço privado na cidade com o objetivo de abrigar centros de compras ao ar livre, sendo localizados próximos aos bairros residenciais ricos. São ocupados por lojas especializadas em produtos e serviços de luxo. O projeto dos Lifestyle Centers é diferente dos shoppings centers tradicionais, que são fechados, pois permite aos consumidores ter uma experiência de compra diferente andando em uma praça ao ar livre com lojas individuais em vista. Esse

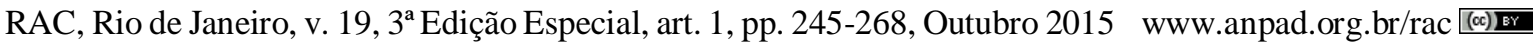


conceito de Lifestyle Center foi desenvolvido no início dos anos 2000 nos Estados Unidos da América (Yan, R.-N., \& Eckman, M. (2009). Are lifestyle centres unique? Consumers' perceptions across locations. International Journal of Retail \& Distribution Management, 37(1), 24-42. doi: 10.1108/09590550910927144).

\section{Referências}

Adriano. (2013, Janeiro 26). Shoppings de BH [Facebook]. Recuperado de https://www.facebook.com/photo.php?fbid=535971059769412\&set=a.391897610843425.10080 $6.336360863063767 \&$ type $=1 \&$ theater

Agostini, L. (2012, dezembro). A proibição de entrada de pessoas em Shopping Centers em razão de raça, preferência sexual e vestimenta. Recuperado de http://www.correaadvogados.com.br/wpcontent/files/Leonardo_Agostini_-_A_Proibio_de_Entrada_de_Pessoas_em_Shopping.pdf

Alice. (2013, Janeiro 23). Shoppings de BH [Facebook]. Recuperado de https://www.facebook.com/photo.php?fbid=535971059769412\&set=a.391897610843425.10080 $6.336360863063767 \&$ type $=1 \&$ theater

Alves, L. A. (2011). Reestruturação urbana e criação de novas centralidades: considerações sobre os shoppings centers. Revista Caminhos de Geografia, 12(37), 171-184.

Amanda. (2013, Janeiro 24). Shoppings de BH [Facebook]. Recuperado de https://www.facebook.com/photo.php?fbid=535971059769412\&set=a.391897610843425.10080 $6.336360863063767 \&$ type $=1 \&$ theater

Amilcka, \& Chocolate. (2006) Som de Preto. Bem Funk Brasil [CD]. Rio de Janeiro: Som Livre.

Andrade, L. M. (2012). O shopping center como figura paradigmática do discurso colonial: racismo e poder na América Latina. Sociedade e Cultura, 15(1), 217-230.

Andrade, L. T. (2002, outubro). Segregação socioespacial na vida cotidiana: o caso dos condomínios fechados. Anais do Encontro Nacional da Associação Nacional de Pós-Graduação e Pesquisa em Ciências Sociais, Caxambu, MG, Brasil, 26.

André. (2013, Janeiro 24). Shoppings de BH [Facebook]. Recuperado de https://www.facebook.com/photo.php?fbid=535971059769412\&set=a.391897610843425.10080 $6.336360863063767 \&$ type $=1 \&$ theater

Andréa. (2013, Janeiro 24). Shoppings de BH [Facebook]. Recuperado de https://www.facebook.com/photo.php?fbid=535971059769412\&set=a.391897610843425.10080 $6.336360863063767 \&$ type $=1 \&$ theater

Antonia. (2013, Janeiro 23). Shoppings de BH [Facebook]. Recuperado de https://www.facebook.com/photo.php?fbid=535971059769412\&set=a.391897610843425.10080 $6.336360863063767 \&$ type $=1 \&$ theater

Antonio. (2013, Janeiro 23). Shoppings de BH [Facebook]. Recuperado de https://www.facebook.com/photo.php?fbid=535971059769412\&set=a.391897610843425.10080 $6.336360863063767 \&$ type $=1 \&$ theater

Associação Brasileira de Shopping Centers. (n.d.). Números dos shoppings nas capitais brasileiras. Recuperado de http://www.portaldoshopping.com.br/numeros-do-setor/shoppings-nas-capitaisbrasileiras

Atkinson, J. D., Rosati, C., Berg, S., Meier, M., \& White, B. (2013). Racial politics in an online community: discursive closures and the potentials for narrative appropriation. Journal of Communication Inquiry, 37(2), 171-185. doi: 10.1177/0196859913482139

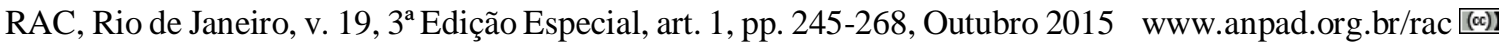


Bahia, C. L. M. (2005). Belo Horizonte: uma cidade para a modernidade mineira. Cadernos de Arquitetura e Urbanismo, 12(13), 185-200.

Barros, J. D’A. (2009). A construção social da cor: diferença e desigualdade na formação da sociedade brasileira. Petrópolis: Vozes.

Bittencourt, R. N. (2012). O sistema panóptico da topologia do Shopping Center, a assepsia humana e a exclusão social da pobreza. Revista Espaço Acadêmico, 12(139), 92-102.

Camila. (2013, Janeiro 23). Shoppings de BH [Facebook]. Recuperado de https://www.facebook.com/photo.php?fbid=535971059769412\&set=a.391897610843425.10080 $6.336360863063767 \&$ type $=1 \&$ theater

Carina. (2013, Janeiro 24). Shoppings de BH [Facebook]. Recuperado de https://www.facebook.com/photo.php?fbid=535971059769412\&set=a.391897610843425.10080 $6.336360863063767 \&$ type $=1 \&$ theater

Carolina. (2013, Janeiro 23). Shoppings de BH [Facebook]. Recuperado de https://www.facebook.com/photo.php?fbid=535971059769412\&set=a.391897610843425.10080 $6.336360863063767 \&$ type $=1 \&$ theater

Carrieri, A. P. (2004). O humor como estratégia discursiva de resistência: as charges do Sinttel/MG. Organizações \& Sociedade, 11(30), 29-48.

Carrieri, A. P. (2012). A gestão ordinária (Tese para concurso de professor titular). Universidade Federal de Minas Gerais, Belo Horizonte, MG, Brasil.

Cavedon, N. R., \& Stefanowski, F. L. (2008). O riso que integra, o riso que separa: identidade organizacional em um sebo de Porto Alegre. Organizações \& Sociedade, 15(46), 137-152.

Clarissa. (2013, Janeiro 23). Shoppings de BH [Facebook]. Recuperado de https://www.facebook.com/photo.php?fbid=535971059769412\&set=a.391897610843425.10080 $6.336360863063767 \&$ type $=1 \&$ theater

Coelho, P. J., Jr. (2011). Executivos negros: racismo e diversidade no mundo empresarial (Tese de doutorado). Universidade de São Paulo, SP, São Paulo, Brasil.

Conceição, E. B. (2009, setembro) A negação da raça nos estudos organizacionais. Anais do Encontro Nacional da Associação Nacional de Pós-Graduação e Pesquisa em Administração. São Paulo, SP, Brasil, 33.

Correa, M. (1996). Sobre a invenção da mulata. Cadernos PAGU, 6(1), 35-50.

Cristina. (2013, Janeiro 23). Shoppings de BH [Facebook]. Recuperado de https://www.facebook.com/photo.php?fbid=535971059769412\&set=a.391897610843425.10080 $6.336360863063767 \&$ type $=1 \&$ theater

Daiane. (2013, Março 26). Shoppings de BH [Facebook]. Recuperado de https://www.facebook.com/photo.php?fbid=535971059769412\&set=a.391897610843425.10080 $6.336360863063767 \&$ type $=1 \&$ theater

Daniele. (2013, Janeiro 23). Shoppings de BH [Facebook]. Recuperado de https://www.facebook.com/photo.php?fbid=535971059769412\&set=a. 391897610843425.10080 $6.336360863063767 \&$ type $=1 \&$ theater

Danilo. (2013, Janeiro 23). Shoppings de BH [Facebook]. Recuperado de https://www.facebook.com/photo.php?fbid=535971059769412\&set=a. 391897610843425.10080 $6.336360863063767 \&$ type $=1 \&$ theater 
Daskalaki, M., Stara, A., \& Imas, M. (2008). The 'Parkour Organisation': inhabitation of corporate spaces. Culture and Organization, 14(1), 49-64. doi: 10.1080/14759550701659029

Departamento Intersindical de Estatística e Estudos Socioeconômicos. (2012). A inserção dos negros nos mercados de trabalho metropolitanos. Sistema de Pesquisa de Emprego e Desemprego. Recuperado de http://www.dieese.org.br/analiseped/2012/2012pednegrosmet.pdf

Dijk, T. A. van (1997). Discourse as interaction in society. In T. A. van Dijk. (Org.), Discourse as social interaction (pp. 1-37). London: Sage.

Eduarda. (2013, Janeiro 23). Shoppings de BH [Facebook]. Recuperado de https://www.facebook.com/photo.php?fbid=535971059769412\&set=a.391897610843425.10080 $6.336360863063767 \&$ type $=1 \&$ theater

Eva. (2013, Janeiro 23). Shoppings de BH [Facebook]. Recuperado de https://www.facebook.com/photo.php?fbid=535971059769412\&set=a.391897610843425.10080 $6.336360863063767 \&$ type $=1 \&$ theater

Faria, A. A. M. (2009). Aspectos de um discurso empresarial. In A. P. Carrieri, L. A. S. Saraiva, T. D. Pimentel, \& P. A. G. Souza-Ricardo (Orgs.), Análise do discurso em estudos organizacionais (pp. 45-52). Curitiba: Juruá.

Felipe. (2013, Janeiro 23). Shoppings de BH [Facebook]. Recuperado de https://www.facebook.com/photo.php?fbid=535971059769412\&set=a.391897610843425.10080 $6.336360863063767 \&$ type $=1 \&$ theater

Fernanda. (2013, Janeiro 23). Shoppings de BH [Facebook]. Recuperado de https://www.facebook.com/photo.php?fbid=535971059769412\&set=a.391897610843425.10080 $6.336360863063767 \&$ type $=1 \&$ theater

Fernando. (2013, Janeiro 23). Shoppings de BH [Facebook]. Recuperado de https://www.facebook.com/photo.php?fbid=535971059769412\&set=a.391897610843425.10080 $6.336360863063767 \&$ type $=1 \&$ theater

Figueiredo, M. D. de, \& Cavedon, N. R. (2012). O espaço organizacional e o espaço da cidade: as diversas formas de apropriação física e simbólica de um centro comercial em Porto Alegre. Gestão e Sociedade, 6(15), 227-253.

Flavia. (2013, Janeiro 23). Shoppings de BH [Facebook]. Recuperado de https://www.facebook.com/photo.php?fbid=535971059769412\&set=a.391897610843425.10080 $6.336360863063767 \&$ type $=1 \&$ theater

Flores-Pereira, M. T., Davel, E., \& Cavedon, N. R. (2008). Drinking beer and understanding organizational culture embodiment. Human Relations, 61(7), 1007-1026. doi: $10.1177 / 0018726708093906$

Freyre, G. (1961). Casa grande e senzala: formação da família brasileira sob o domínio da economia patriarcal. Rio de Janeiro: José Olympio.

Furtado, R. A., Carrieri, A. P., \& Bretas, P. F. F. (2011, setembro). Humor na internet: trabalhadores utilizam nova estratégia para protestar contra demissões e terceirizações. Anais do Encontro Nacional da Associação Nacional de Pós-Graduação e Pesquisa em Administração, Rio de Janeiro, RJ, Brasil, 35.

Gergen, K. J., Gergen, M., \& Barrett, F. J. (2004). Dialogue: life and death of the organization. In D. Grant, C. Hardy, C. Oswick, \& L. L. Putnam (Eds.), The SAGE Handbook of organizational discourse (pp. 79-104). London: SAGE. 
Gilson. (2013, Janeiro 23). Shoppings de BH [Facebook]. Recuperado de https://www.facebook.com/photo.php?fbid=535971059769412\&set=a.391897610843425.10080 $6.336360863063767 \&$ type $=1 \&$ theater

Guilherme. (2013, Janeiro 27). Shoppings de BH [Facebook]. Recuperado de https://www.facebook.com/photo.php?fbid=535971059769412\&set=a.391897610843425.10080 $6.336360863063767 \&$ type $=1 \&$ theater

Gustavo. (2013, Janeiro 23). Shoppings de BH [Facebook]. Recuperado de https://www.facebook.com/photo.php?fbid=535971059769412\&set=a.391897610843425.10080 $6.336360863063767 \&$ type $=1 \&$ theater

Hall, S. (1999). A identidade cultural na pós-modernidade. Rio de Janeiro: DP\&A.

Herzog, L. A. (2013). Barra da Tijuca: the political economy of a global suburb in Rio de Janeiro, Brazil. Latin American Perspectives, 40(2), 118-134. doi: 10.1177/0094582X12467765

Ikejiaku, B. V. (2009). 'Crime', poverty, political corruption and conflict in apartheid and post apartheid South Africa: the implications on economic development. African Journal of Political Science and International Relations, 3(10), 451-459.

Imas, J. M., \& Weston, A. (2012). From harare to Rio de Janeiro: Kukiya-Favela organization of the excluded. Organization, 19(2) 205-227. doi: 10.1177/1350508411429397

Irigaray, H. A. R., Saraiva, L. A. S., \& Carrieri, A. P. (2010). Humor e discriminação por orientação sexual no ambiente organizacional. Revista de Administração Contemporânea, 14(5), 890-906. Recuperado de http://www.scielo.br/pdf/rac/v14n5/v14n5a08.pdf. doi: 10.1590/S141565552010000500008

Isabela. (2013, Janeiro 23). Shoppings de BH [Facebook]. Recuperado de https://www.facebook.com/photo.php?fbid=535971059769412\&set=a.391897610843425.10080 $6.336360863063767 \&$ type $=1 \&$ theater

João. (2013, Janeiro 24). Shoppings de BH [Facebook]. Recuperado de https://www.facebook.com/photo.php?fbid=535971059769412\&set=a.391897610843425.10080 $6.336360863063767 \&$ type $=1 \&$ theater

Julia. (2013, Janeiro 24). Shoppings de BH [Facebook]. Recuperado de https://www.facebook.com/photo.php?fbid=535971059769412\&set=a.391897610843425.10080 $6.336360863063767 \&$ type $=1 \&$ theater

Kenny, E. J., \& Briner, R. B. (2013). Increases in salience of ethnic identity at work: the roles of ethnic assignation and ethnic identification. Human Relations, 66(5) 725-748. doi: $10.1177 / 0018726712464075$

Laís. (2013, Janeiro 23). Shoppings de BH [Facebook]. Recuperado de https://www.facebook.com/photo.php?fbid=535971059769412\&set=a.391897610843425.10080 $6.336360863063767 \&$ type $=1 \&$ theater

Larissa. (2013, Janeiro 26). Shoppings de BH [Facebook]. Recuperado de https://www.facebook.com/photo.php?fbid=535971059769412\&set=a.391897610843425.10080 $6.336360863063767 \&$ type $=1 \&$ theater

Laura. (2013, Janeiro 23). Shoppings de BH [Facebook]. Recuperado de https://www.facebook.com/photo.php?fbid=535971059769412\&set=a.391897610843425.10080 $6.336360863063767 \&$ type $=1 \&$ theater

Leitão, L. (2005). Quando um muro separa e nenhuma ponte une. Cadernos Metrópole, (13), 229-253. 
Letícia. (2013, Janeiro 23). Shoppings de BH [Facebook]. Recuperado de https://www.facebook.com/photo.php?fbid=535971059769412\&set=a.391897610843425.10080 $6.336360863063767 \&$ type $=1 \&$ theater

Lorena. (2013, Janeiro 24). Shoppings de BH [Facebook]. Recuperado de https://www.facebook.com/photo.php?fbid=535971059769412\&set=a.391897610843425.10080 $6.336360863063767 \&$ type $=1 \&$ theater

Lucas. (2013, Janeiro 23). Shoppings de BH [Facebook]. Recuperado de https://www.facebook.com/photo.php?fbid=535971059769412\&set=a.391897610843425.10080 $6.336360863063767 \&$ type $=1 \&$ theater

Luísa. (2013, Janeiro 23). Shoppings de BH [Facebook]. Recuperado de https://www.facebook.com/photo.php?fbid=535971059769412\&set=a.391897610843425.10080 $6.336360863063767 \&$ type $=1 \&$ theater

Maingueneau, D. (2006). Termos-chave da análise do discurso. Belo Horizonte: UFMG.

Marcelo. (2013, Janeiro 23). Shoppings de BH [Facebook]. Recuperado de https://www.facebook.com/photo.php?fbid=535971059769412\&set=a.391897610843425.10080 $6.336360863063767 \&$ type $=1 \&$ theater

Maria. (2013, Janeiro 23). Shoppings de BH [Facebook]. Recuperado de https://www.facebook.com/photo.php?fbid=535971059769412\&set=a.391897610843425.10080 $6.336360863063767 \&$ type $=1 \&$ theater

Mariana. (2013, Janeiro 23). Shoppings de BH [Facebook]. Recuperado de https://www.facebook.com/photo.php?fbid=535971059769412\&set=a.391897610843425.10080 $6.336360863063767 \&$ type $=1 \&$ theater

Marina. (2013, Janeiro 26). Shoppings de BH [Facebook]. Recuperado de https://www.facebook.com/photo.php?fbid=535971059769412\&set=a.391897610843425.10080 $6.336360863063767 \&$ type $=1 \&$ theater

Mateus. (2013, Janeiro 26). Shoppings de BH [Facebook]. Recuperado de https://www.facebook.com/photo.php?fbid=535971059769412\&set=a.391897610843425.10080 $6.336360863063767 \&$ type $=1 \&$ theater

Meneguello, A., \& Amoroso, P. R. (2006). O Funk desce o morro, invade o asfalto e convida o outro para dançar. Revista Científica, 5(5), 103-105.

Michele. (2013, Janeiro 23). Shoppings de BH [Facebook]. Recuperado de https://www.facebook.com/photo.php?fbid=535971059769412\&set=a.391897610843425.10080 $6.336360863063767 \&$ type $=1 \&$ theater

Miguel. (2013, Janeiro 23). Shoppings de BH [Facebook]. Recuperado de https://www.facebook.com/photo.php?fbid=535971059769412\&set=a.391897610843425.10080 $6.336360863063767 \&$ type $=1 \&$ theater

Mountian, I., \& Calvo-Gonzalez, E. (2012). II. 'Race', class and affirmative action in Brazil: reflections from a feminist perspective. Feminism \& Psychology, 22(2), 240-248. doi: $10.1177 / 0959353511415965$

Moura, C. S. S. (2012). "No shopping nóis é patrão!”: sociabilidade e lazer entre jovens de periferia (Dissertação de mestrado). Universidade Federal da Bahia, Salvador, BA, Brasil.

Munanga, K. (2005/2006). Algumas considerações sobre "raça", ação afirmativa e identidade negra no Brasil: fundamentos antropológicos. Revista USP, (68), 45-57. 
Natalia. (2013, Janeiro 23). Shoppings de BH [Facebook]. Recuperado de https://www.facebook.com/photo.php?fbid=535971059769412\&set=a.391897610843425.10080 $6.336360863063767 \&$ type $=1 \&$ theater

Nkomo, S. M. (2011). A postcolonial and anti-colonial reading of 'African' leadership and management in organization studies: tensions, contradictions and possibilities. Organization, 18(3) 365-386. doi: $10.1177 / 1350508411398731$

Nogueira, O. (2007). Preconceito racial de marca e preconceito racial de origem: sugestão de um quadro de referência para a interpretação do material sobre relações raciais no Brasil. Tempo Social, 19(1), 287-308. doi: 10.1590/S0103-20702007000100015

Nogueira, P. S. (2010). Práticas de arquitetura para demandas populares: a experiência dos arquitetos da família (Dissertação de mestrado). Universidade Federal de Minas Gerais, Belo Horizonte, MG, Brasil.

Orlandi, E. P. (2009). Análise de discurso: princípios e procedimentos. Campinas: Pontes.

Paola. (2013, Janeiro 23). Shoppings de BH [Facebook]. Recuperado de https://www.facebook.com/photo.php?fbid=535971059769412\&set=a.391897610843425.10080 $6.336360863063767 \&$ type $=1 \&$ theater

Pátio Savassi. (n.d.). Institucional. Recuperado de http://patiosavassi.com/institucional/

Paulo. (2013, Janeiro 23). Shoppings de BH [Facebook]. Recuperado de https://www.facebook.com/photo.php?fbid=535971059769412\&set=a.391897610843425.10080 $6.336360863063767 \&$ type $=1 \&$ theater

Pêcheux, M., \& Fuchs, C. (1997). A propósito da análise automática do discurso: atualização e perspectivas. In F. Gadet \& T. Hak (Orgs.), Por uma análise automática do discurso: uma introdução à obra de Michel Pêcheux (pp. 163-252). Campinas: Unicamp.

Pereira, C., Torres, A. R. R., \& Almeida, S. T. (2003). Um estudo do preconceito na perspectiva das representações sociais: análise da influência de um discurso justificador da discriminação no preconceito racial. Psicologia - Reflexão e Crítica, 16(1), 95-107. doi: 10.1590/S010279722003000100010

Rafael. (2013, Janeiro 23). Shoppings de BH [Facebook]. Recuperado de https://www.facebook.com/photo.php?fbid=535971059769412\&set=a.391897610843425.10080 $6.336360863063767 \&$ type $=1 \&$ theater

Raynor, S. (2009). My first black Barbie: transforming the image. Cultural Studies - Critical Methodologies, 9(2), 179-185. doi: 10.1177/1532708608326607

Rebeca. (2013, Janeiro 24). Shoppings de BH [Facebook]. Recuperado de https://www.facebook.com/photo.php?fbid=535971059769412\&set=a.391897610843425.10080 $6.336360863063767 \&$ type $=1 \&$ theater

Ricardo. (2013, Janeiro 23). Shoppings de BH [Facebook]. Recuperado de https://www.facebook.com/photo.php?fbid=535971059769412\&set=a.391897610843425.10080 $6.336360863063767 \&$ type $=1 \&$ theater

Roberta. (2013, Janeiro 23). Shoppings de BH [Facebook]. Recuperado de https://www.facebook.com/photo.php?fbid=535971059769412\&set=a.391897610843425.10080 $6.336360863063767 \&$ type $=1 \&$ theater

Roberto. (2013, Janeiro 23). Shoppings de BH [Facebook]. Recuperado de https://www.facebook.com/photo.php?fbid=535971059769412\&set=a.391897610843425.10080 $6.336360863063767 \&$ type $=1 \&$ theater 
Rodrigo. (2013, Janeiro 23). Shoppings de BH [Facebook]. Recuperado de https://www.facebook.com/photo.php?fbid=535971059769412\&set=a.391897610843425.10080 $6.336360863063767 \&$ type $=1 \&$ theater

Rosa, A. R. (2012, setembro). Relações raciais e estudos organizacionais no Brasil: dimensões esquecidas de um debate que (ainda) não foi feito. Anais do Encontro Nacional da Associação Nacional de Pós-Graduação e Pesquisa em Administração. Rio de Janeiro, RJ, Brasil, 36.

Sansone, L. (1996). Nem somente preto ou negro: o sistema de classificação racial no Brasil que muda. Afro-Ásia, 18(1), 165-187.

Soares, M. A. D. (2012). Look, blackness in Brazil!: disrupting the grotesquerie of racial representation in Brazilian visual culture. Cultural Dynamics, 24(1), 75-101. doi: 10.1177/0921374012452812

Tatiana. (2013, Janeiro 23). Shoppings de BH [Facebook]. Recuperado de https://www.facebook.com/photo.php?fbid=535971059769412\&set=a.391897610843425.10080 $6.336360863063767 \&$ type $=1 \&$ theater

Tiago. (2013, Janeiro 23). Shoppings de BH [Facebook]. Recuperado de https://www.facebook.com/photo.php?fbid=535971059769412\&set=a.391897610843425.10080 $6.336360863063767 \&$ type $=1 \&$ theater

Valter. (2013, Janeiro 23). Shoppings de BH [Facebook]. Recuperado de https://www.facebook.com/photo.php?fbid=535971059769412\&set=a.391897610843425.10080 $6.336360863063767 \&$ type $=1 \&$ theater

Vanessa. (2013, Janeiro 23). Shoppings de BH [Facebook]. Recuperado de https://www.facebook.com/photo.php?fbid=535971059769412\&set=a.391897610843425.10080 $6.336360863063767 \&$ type $=1 \&$ theater

Vitoria (2013, Janeiro 23). Shoppings de BH [Facebook]. Recuperado de https://www.facebook.com/photo.php?fbid=535971059769412\&set=a.391897610843425.10080 $6.336360863063767 \&$ type $=1 \&$ theater

Worby, E. (2009). The play of race in a field of urban desire: soccer and spontaneity in post-apartheid Johannesburg. Critique of Anthropology, 29(1), 105-123. doi: 10.1177/0308275X08101030

\title{
Dados dos Autores
}

\author{
Marco César Ribeiro Nascimento \\ Av. Doutor Sylvio Menicucci, 1001, Kennedy, 37200-000, Lavras, MG, Brasil. E-mail: marcocesar82@ hotmail.com \\ Josiane Silva de Oliveira \\ UFRGS, Av. Paulo Gama, 110, Farroupilha, 90040-060, Porto Alegre, RS, Brasil. E-mail: oliveira.josianesilva@ gmail.com \\ Juliana Cristina Teixeira \\ UFMG, Av. Antônio Carlos, 6627, 31270-901, Belo Horizonte, MG, Brasil. E-mail: julianacteixeira@ yahoo.com.br \\ Alexandre de Pádua Carrieri \\ UFMG, Av. Antônio Carlos, 6627, 31270-901, Belo Horizonte, MG, Brasil. E-mail: alexandre@ face.ufmg.br
}

